\title{
Blood Volume and Body Fluid Compartments in Lambs with Aortopulmonary Left-to-Right Shunts
}

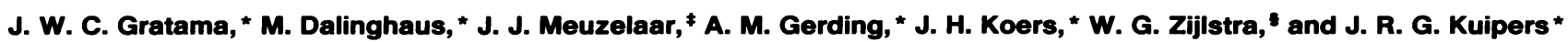

* Departments of Pediatrics, ${ }^{\ddagger}$ Thoracic Surgery, and ${ }^{\S}$ Physiology, University of Groningen, Groningen, The Netherlands

\begin{abstract}
A left-to-right shunt is accompanied by an increased plasma and blood volume. Since this is likely realized through renin/ aldosterone-mediated salt and water retention, other body fluid compartments may be changed too. Therefore, we studied blood volume and body fluid compartments by a single-injection, triple-indicator dilution technique in nine 8-wk-old lambs with an aortopulmonary left-to-right shunt $(55 \pm 3 \%$ of left ventricular output; mean \pm SEM) and in 11 control lambs, 2.5 wk after surgery. Systemic blood flow was maintained at the same level as in control lambs, but the aortic pressure of the shunt lambs was lower. Blood volume in shunt lambs was larger than in control lambs $(110 \pm 6 \mathrm{vs} .84 \pm 7 \mathrm{ml} / \mathrm{kg}, P<0.001)$ through an increase in plasma volume, which correlated significantly with the magnitude of the left-to-right shunt $(r=0.81, P$ $<0.01$ ). Red blood cell volume was equal to that of control lambs. Evidence was obtained that the increase in plasma volume was induced by a transient increase in renin (8.0 $\pm 2.2 \mathrm{vs.}$ $\left.1.6 \pm 0.2 \mathrm{nmol} \cdot \mathrm{I}^{-1} \cdot \mathrm{h}^{-1} ; P<0.02\right)$ and aldosterone $(0.51 \pm 0.14$ vs. $0.24 \pm 0.09 \mathrm{nmol} /$ liter ) concentrations. Interstitial water volume, however, was not significantly different from that in control lambs. The amount of intravascular protein was significantly higher than in control lambs $(5.0 \pm 0.3$ vs. $3.5 \pm 0.2$ $\mathrm{g} / \mathrm{kg}$ body mass, $P<0.001$ ). There were no significant differences in intracellular and total body water volumes between the two groups. We conclude that the increased amount of intravascular protein confines the fluid retained by the kidneys to the vascular compartment. (J. Clin. Invest. 1992. 90:1745-1752.) Key words: congenital heart disease - chronic volume load • plasma protein • deuterium oxide • ferrocyanide $\bullet$ Evans blue
\end{abstract}

\section{Introduction}

In the presence of a left-to-right shunt, a part of the cardiac output does not participate in the systemic circulation but recirculates into the lungs, which results in a decreased effective circulating blood volume, at least in the early phase (1). One of the adaptations to a left-to-right shunt hence consists of an increase in blood volume as has been demonstrated in patients

This work was presented at the Annual Scientific Session of the Society for Pediatric Research, 1-4 May 1989, Washington, DC.

Address correspondence and reprint requests to Jaap $R$. G. Kuipers, M. D., University Hospital, Department of Pediatrics, Division of Pediatric Cardiology, Oostersingel 59, 9713 EZ Groningen, The Netherlands.

Received for publication 31 May 1991 and in revised form 15 May 1992.

J. Clin. Invest.

(c) The American Society for Clinical Investigation, Inc. $0021-9738 / 92 / 11 / 1745 / 08 \quad \$ 2.00$

Volume 90, November 1992, 1745-1752 and dogs with arteriovenous fistulas $(2,3)$. Although left-toright shunts caused by congenital heart defects lead to rather different hemodynamic situations than aortocaval left-to-right shunts, blood volume is also increased in children with left-toright shunts (4). The increase in blood volume is realized through a plasma volume increase $(4,5)$. This probably occurs through a transient increase in renin and aldosterone concentrations and sodium and water retention as observed in adult dogs with aortocaval fistulas $(5,6)$. Although young infants may show a different hormonal reaction to circulatory stress $(7,8)$, increased renin and aldosterone concentrations in infants and lambs with left-to-right shunts suggests a similar mechanism for plasma volume increase as in adults $(9,10)$.

Increased aldosterone concentrations lead to isosmotic fluid retention, which may not only increase the plasma volume but also the interstitial fluid volume. Although changes in blood volume in children with left-to-right shunts have been documented (4), little is known about the changes, if any, in other body fluid compartments. In dogs with aortocaval fistulas, edema frequently occurs, indicating that the hormonal changes not only lead to an increased plasma volume but also to an increased interstitial fluid volume $(6,11,12)$. Edema, however, is not frequently observed in children with left-toright shunts. In addition, we previously have not found a significant difference in body mass between shunt and control lambs (13-15), suggesting either that no large increase in extracellular fluid volume occurs or that the increase in extracellular fluid volume is accompanied by a decrease in intracellular fluid volume. Renin/aldosterone-induced fluid retention, however, is not necessarily accompanied by an increase in both compartments of the extracellular fluid volume, as was demonstrated by the increased blood volume induced by chronic exercise training. The retained fluid is then kept in the vascular compartment through an increase in the total amount of plasma protein (16).

We put forward the hypothesis that in lambs with an aortopulmonary left-to-right shunt the effective circulating blood volume is increased through an increase in plasma volume, and that the fluid retained by the kidneys is kept within the vascular compartment by an increase in intravascular protein, while no substantial changes in interstitial and intracellular fluid volume occur. To test our hypothesis we measured the body fluid compartments in lambs with and without an aortopulmonary left-to-right shunt, 2.5 wk after surgery. To evaluate the underlying mechanism we further measured plasma renin activity, aldosterone, and arginine-vasopressin and plasma protein concentrations. Because cardiac disease accompanied by inadequate systemic blood flow may also lead to plasma and interstitial volume expansion independent of the presence of a left-toright shunt $(5,17-20)$, we determined arterial $\mathrm{pH}$ and blood gases, glomerular filtration rate, plasma urea, creatinin, and electrolytes in addition to hemodynamic parameters to assess circulatory status of the lambs $(21,22)$. 


\section{Methods}

We studied 20 6-8-wk-old lambs of mixed breed with documented dates of birth. They were divided into two groups: 9 lambs with an aortopulmonary left-to-right shunt and 11 lambs without a shunt. Until the day of study each lamb remained with its mother.

Surgical procedure. Surgical preparation, catheter care, and antibiotic administration were performed as described previously $(13,15)$. In brief, after induction of halothane anesthesia, we performed a thoracotomy through the fourth intercostal space and sutured a Goretex® conduit $(6 \mathrm{~mm}$ inner diameter [i.d.]; W. L. Gore and Assoc. Inc., Flagstaff, AZ) between the descending aorta and the main pulmonary artery at the level of the fibrotic string of the ductus arteriosus. Precalibrated electromagnetic flow transducers (10-15 mm i.d.; Skalar Medical, Delft, The Netherlands) were placed around the ascending aorta just above the coronary arteries and around the pulmonary artery proximal to the conduit. Polyvinyl catheters were placed in the ascending aorta, pulmonary artery, right ventricle, and left and right atrium. Finally, the chest wall was closed in layers, and the catheters and flow probe cables were led through a subdermal tunnel to a cloth pouch, sewn to the left flank of the lamb. For the control lambs surgical instrumentation was the same except for the conduit, the flow transducer around the pulmonary artery, and the right ventricular catheter.

Experimental protocol. $17 \pm 1$ (range 13-23) d after surgery, we determined plasma, extracellular, and total body water volumes by means of a single-injection, triple-indicator dilution technique, which allows for calculation of these volumes from the plasma disappearance curves of the indicators (23). The indicators used were Evans blue, ferrocyanide, and deuterium oxide $\left(\mathrm{D}_{2} \mathrm{O}\right)$, respectively (24-26). On the day of study the lamb was weighed, brought to the experimental room, and put in a sling. A freshly prepared solution containing the three indicators was injected into the pulmonary artery. Blood samples (2-4 ml) were withdrawn from the aortic catheter just before and at 3 , $6,9,12,15,20,25,30,40,50,60,75,90,105,120,135,150,165$, and $180 \mathrm{~min}$ after the injection for determination of the concentration of the indicators. The sample withdrawn before the injection served for obtaining a blank reference value. Zero time was chosen half way between start and finish of the injection, which took $\sim 20 \mathrm{~s}$. All blood was collected in dry-heparinized tubes. The hematocrit was determined in duplicate in the blood samples withdrawn before and at 20,30,40,50, and $60 \mathrm{~min}$ after the injection. Before the injection of the indicators, an additional $10 \mathrm{ml}$ of blood was withdrawn from the aortic catheter for determination of plasma renin activity; plasma arginine vasopressin and aldosterone concentrations; plasma osmolality; and protein, electrolyte, creatinin, and urea concentrations. After the withdrawal of each blood sample an equal volume of saline $(9 \mathrm{~g} /$ liter $)$ was injected into the pulmonary artery to replace volume loss during the experiment; a total volume of 60 to $70 \mathrm{ml}$ blood was withdrawn. Between the 150 th and the 180th minute of the study we measured systemic and pulmonary blood flows and aortic, pulmonary, left and right atrial pressures. This was done at 5-min intervals. At 165 and $180 \mathrm{~min}$ we withdrew a blood sample $(0.5 \mathrm{ml})$ from the aortic catheter for determination of hemoglobin concentration, $\mathrm{pH}, \mathrm{PCO}_{2}, \mathrm{PO}_{2}$, and plasma $\mathrm{HCO}_{3}^{-}$concentration.

Since it has been shown in a recent study that changes in renin and aldosterone take place early after creation of a left-to-right shunt (6), we determined hormone concentrations on day 4 as well as at $2.5 \mathrm{wk}$ after surgery in the last three shunt and two control lambs of our study. In one additional shunt and one control lamb hormones were also determined at day 4 after surgery, but measurements could not be obtained at $2.5 \mathrm{wk}$.

Measurements and calculations. The precalibrated electromagnetic flow transducers were connected to flow meters (Skalar MDL 400; Skalar Medical). Systemic and pulmonary blood flow of the shunt lambs were obtained from the pulmonary arterial and aortic flow transducer, respectively; the systemic blood flow of the control lambs was obtained from the aortic flow transducer (13). Zero flow was obtained during diastole when the blood flow rate above the aortic and pulmo- nary valves is zero. The position of the aortic flow transducer was distal to the origin of the coronary arteries. To obtain total left ventricular output, the flow signal from the aortic transducer should be modified by adding the coronary blood flow (27). In experiments with identically instrumented shunt and control lambs in our laboratory in which radioactive-labeled microspheres were used, we consistently found coronary blood flow to be $4 \%$ of left ventricular output, in the shunt as well as in the control lambs. On the basis of these findings we multiplied the aortic flow transducer signal by 1.04 to obtain total left ventricular output (15). Heart rate was obtained from the blood flow signal. Aortic, pulmonary arterial, left atrial, and right atrial pressures were measured with pressure transducers (Gould P23 ID; Spectramed Inc., Oxnard, CA) referenced to atmospheric pressure with zero obtained with the pressure transducer at the right atrial level. All variables were recorded on an ink-jet recorder (Elema Mingograf 800; Siemens-Elema AB, Solna, Sweden). Left-to-right shunt flow was calculated by subtracting systemic blood flow from pulmonary blood flow. Left-to-right shunt fraction was obtained by dividing left-to-right shunt flow by pulmonary blood flow. Systemic vascular resistance was calculated as the difference between mean aortic and right atrial pressures divided by systemic blood flow: Similarly, pulmonary vascular resistance was calculated as the difference between mean pulmonary and left atrial pressures divided by pulmonary blood flow.

Hemoglobin concentration was determined in duplicate using arterial blood with a hemoxymeter (OSM2; Radiometer, Copenhagen, Denmark). $\mathrm{pH}, \mathrm{PCO}_{2}, \mathrm{PO}_{2}$, and plasma $\mathrm{HCO}_{3}^{-}$concentration were determined with a blood-gas analyzer (ABL-2; Radiometer). Hematocrit was determined by the microcapillary method. Total plasma protein concentration was determined spectrophotometrically (28). Plasma osmolality was determined in duplicate with an osmometer (Osmomat 030; Gonotec, GmBH, Berlin, Germany); sodium and potassium concentrations were determined with a photometer (Flame Photometer IL343; Instrumentation Laboratory Inc., Lexington, MA); and the concentrations of chloride, urea, and creatinin were determined with an automatic chemical analyzer (ACA III; Du Pont Company, Clinical System Division, Wilmington, DE). Blood for measurement of plasma renin activity, plasma arginine-vasopressin, and aldosterone concentrations was collected in dry EDTA containing tubes and immediately centrifuged at $4^{\circ} \mathrm{C}$, then stored at $-20^{\circ} \mathrm{C}$ until determination by radioimmunoassay (29). For plasma renin activity and plasma arginine-vasopressin, commercial kits were used (Rianen; DuPont Company, Billerica, MA, and Vasopressin Rapid; Bühlmann Laboratories A. G., Basel, Switzerland, respectively).

Total plasma protein was further subdivided into albumin and globulin fractions $(\alpha 1, \alpha 2, \beta$, and $\gamma)$ by electrophoresis on cellulose acetate, using an automatic electrophoresis system (Haite 300; Olympus Optical Corp. Ltd., Tokyo, Japan) in duplicate and the average value for each lamb was calculated. Because we could not perform this determination in all the lambs of the present study, we performed additional measurements in similarly instrumented (eight shunt and seven control) lambs (30).

Body fluid compartments and glomerular filtration rate. We injected into the lamb $1 \mathrm{ml} / \mathrm{kg}$ of a solution containing $0.4 \mathrm{mmol} /$ liter Evans blue (E. Merck, Darmstadt, Germany) and $100 \mathrm{mmol} /$ liter sodium ferrocyanide (BDH Chemicals Ltd., Poole, England) in $\mathrm{D}_{2} \mathrm{O}$ 99.8\% (Uvasol; E. Merck). The exact amount of each indicator administered was calculated from density and mass of the solution injected, determined by weighing the syringe to the nearest $0.001 \mathrm{~g}$ before and after the injection. The solution was prepared shortly before injection to avoid formation of free cyanide.

After the experiment, all samples were centrifuged and plasma and red blood cells separately stored at $-20^{\circ} \mathrm{C}$ until determination of the indicator concentrations. Concentrations of Evans blue, sodium ferrocyanide, and $\mathrm{D}_{2} \mathrm{O}$ were measured spectrophotometrically as described by $\mathrm{Zweens}$ and coworkers $(24,26,31)$. Evans blue concentration was determined in the samples that were withdrawn at 20,30,40,50, and $60 \mathrm{~min}$. A volume of $0.8 \mathrm{ml}$ of polyethylene glycol $(240 \mathrm{~g} /$ liter $)$ was mixed with an equal volume of plasma to precipitate the nonalbumin 
plasma proteins that may interfere with the measurement of the Evans blue absorbance (24). After $10 \mathrm{~min}$ the mixture was centrifuged at $7,000 \mathrm{~g}$ for $10 \mathrm{~min}$ and the absorbance of the supernatant measured against a similarly processed plasma blank at the wavelength of maximum absorbance ( $620 \mathrm{~nm}$ for lamb plasma) by means of a spectrophotometer (model 100-40; Hitachi Ltd., Tokyo, Japan). The absorbances were converted to plasma concentrations of Evans blue by using a calibration line determined before each set of measurements.

Sodium ferrocyanide concentration was determined in all plasma samples. To $0.5 \mathrm{ml}$ plasma, $4.5 \mathrm{ml}$ of a solution of trichloric acetic acid $(0.14 \mathrm{~mol} /$ liter $)$ and perchloric acid $(1.10 \mathrm{~mol} /$ liter $)$ in $\mathrm{H}_{2} \mathrm{O}$ was added and well mixed. After $10 \mathrm{~min}$ the mixture was centrifuged for 10 min at $7,000 \mathrm{~g}$. To $4 \mathrm{ml}$ of the supernatant was added $1 \mathrm{ml}$ of a solution of $5 \mathrm{~g}$ /liter $\mathrm{FeSO}_{4}$ and $\mathrm{H}_{2} \mathrm{SO}_{4}(90 \mathrm{mmol} /$ liter $)$ in $\mathrm{H}_{2} \mathrm{O}$, prepared at least 1 wk in advance (31). After 25 min a blue color had developed (Prussian blue, $\mathrm{Fe}\left[\mathrm{Fe}(\mathrm{CN})_{6}\right]^{-}$), which remained stable for $\geq 15 \mathrm{~min}$, during which the absorbance of the solution was measured at $700 \mathrm{~nm}$ against a similarly treated plasma blank by means of a grating spectrophotometer (model CF4; Optica, Milan, Italy). The absorbances were converted to plasma concentrations of ferrocyanide by using a calibration line determined before each set of measurements. For the determination of the extracellular fluid volume, the ferrocyanide concentration in plasma $\left(C_{\mathrm{p}}\right)$ was converted to the concentration in plasma water $\left(C_{\mathrm{pw}}\right)$, by correcting for the plasma protein volume using Eq. 1.

$C_{\mathrm{pw}}=C_{\mathrm{p}} \cdot 1,000 /\left(1,000-0.75 \cdot \mathrm{C}_{\mathrm{TP}}^{\mathrm{p}}\right)$,

where $\mathrm{C}_{\mathrm{TP}}{ }^{\mathrm{p}}$ denotes total plasma protein concentration ( $\mathrm{g} /$ liter) and $0.75(\mathrm{ml} / \mathrm{g})$ is the specific volume of plasma protein.

To determine the concentration of $\mathrm{D}_{2} \mathrm{O}, \sim 0.5 \mathrm{ml}$ of red cells were vacuum sublimated to near total dryness and the condensate was collected in vessels immersed in liquid nitrogen. By using red blood cells instead of plasma the amount of blood needed was reduced (26). The absorbance of the condensate was determined at $4,023 \mathrm{~nm}$ by means of an infrared spectrophotometer (model 177; Perkin Elmer Corporation, Norwalk, CT). The instrument was connected to a digital read-out for simultaneous display of the absorbance and the temperature in the cuvette. A sealed liquid cell with $\mathrm{CaF}_{2}$ windows and a light path of 0.01 $\mathrm{cm}$ was used. A piece of ordinary window glass having the same absorption as a water-filled cell at the wavelength used (26) was used in the reference beam. The absorbances were converted to $\mathrm{D}_{2} \mathrm{O}$ concentrations by using a calibration line determined before each set of measurements.

Plasma volume $\left(V_{\mathrm{p}}\right)$ was calculated with Eq. 2.

$V_{\mathrm{p}}=m_{\mathrm{i}} / C_{0}^{\mathrm{p}}$,

where $m_{\mathrm{i}}$ denotes the exact amount of indicator injected, and $C_{0}{ }^{\mathrm{p}}$ the plasma concentration of the indicator at time zero. $C_{0}{ }^{\mathrm{p}}$ was obtained by extrapolation, assuming mono-exponential elimination (24):

$C_{\mathrm{t}}=C_{0} \cdot \mathrm{e}^{-\alpha}$,

where $\alpha$ was obtained from the linear regression equation of the monoexponential tail of the log plasma Evans blue concentration versus time curve, between 20 and $60 \mathrm{~min}$ after the injection of the indicator (Fig. 1). Similarly, total body water volume $\left(V_{\mathrm{bw}}\right)$ was calculated with Eq. 4:

$V_{\mathrm{bw}}=m_{\mathrm{i}} / C_{0}{ }^{\mathrm{pw}}$,

where $\mathrm{C}_{0}{ }^{\mathrm{pw}}$ denotes the plasma water concentration of the indicator at time zero. $\mathrm{C}_{0}{ }^{\mathrm{pw}}$ is usually obtained by extrapolation to time zero of the mono-exponential tail of the $\log$ plasma water $\mathrm{D}_{2} \mathrm{O}$ concentration versus time curve (26). However, in the first four lambs we found that the $\mathrm{D}_{2} \mathrm{O}$ plasma water concentration did not significantly change with time between 40 and $180 \mathrm{~min}$ after injection (Fig. 1). Therefore, we calculated the $\mathrm{D}_{2} \mathrm{O}$ concentration at time zero as the mean of the concentrations at $50,60,75,90,105$, and $120 \mathrm{~min}$.

Because the elimination time of ferrocyanide, the indicator for the extracellular fluid volume, is short relative to the equilibration time over its distribution space, the multiexponential character of the disap-
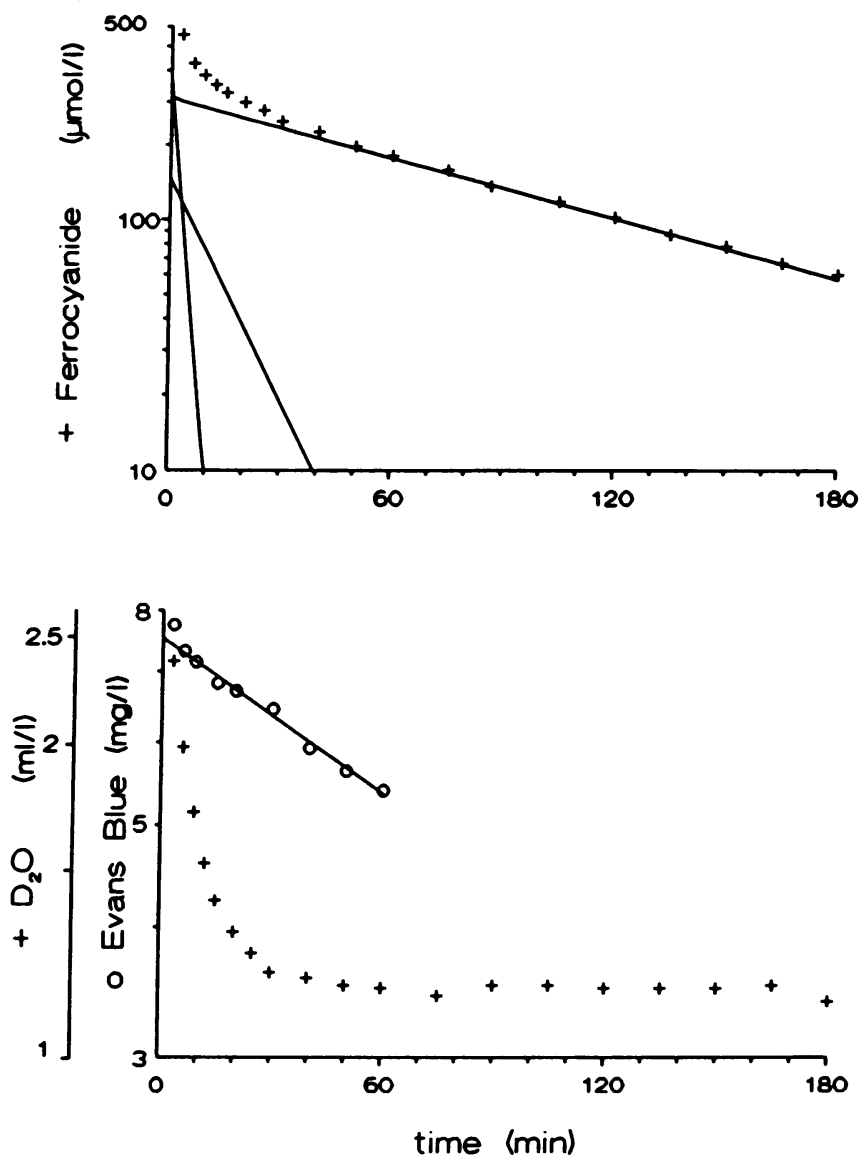

Figure 1. Plasma indicator concentrations, semilogarithmically plotted versus time after injection of the indicators in a single experiment. The upper panel shows ferrocyanide concentrations in plasma water $(+)$. The three lines represent three exponential functions, obtained by curve-stripping. The lower panel shows concentrations of Evans blue $(0)$ and deuterium oxide $(+)$. The line represents the exponential function that fits the mono-exponential tail of the Evans blue curve.

pearance curve must be taken into account in calculating the concentration at time zero (25). For the concentration-time curve Eq. 5 was assumed to be valid:

$C_{\mathrm{t}}=\mathrm{A} \cdot \mathrm{e}^{-\mathrm{ex}}+\mathrm{B} \cdot \mathrm{e}^{-\mathrm{er}}+\mathrm{C} \cdot \mathrm{e}^{-x}$

The coefficients and exponents of the distinct components of the disappearance curve, A, $\alpha, \mathrm{B}, \beta, \mathrm{C}$, and $\gamma$ were obtained by means of curve stripping of the log plasma water ferrocyanide concentration versus time curve into three, rarely two, exponential curves (Fig. 1), and the extracellular fluid volume $\left(V_{\text {ec }}\right)$ was calculated by means of Eq. 6 $(23,25)$.

$V_{\mathrm{ec}}=m_{\mathrm{i}} \cdot \frac{\frac{\mathrm{A}}{\alpha^{2}}+\frac{\mathrm{B}}{\beta^{2}}+\frac{\mathrm{C}}{\gamma^{2}}}{\left[\frac{\mathrm{A}}{\alpha}+\frac{\mathrm{B}}{\beta}+\frac{\mathrm{C}}{\gamma}\right]^{2}}$

The blood volume was calculated with the Eq. 7 .

$V_{\mathrm{b}}=V_{\mathrm{p}} \cdot 100 /(100-0.92 \cdot H)$,

where $V_{\mathrm{b}}$ denotes blood volume, $V_{\mathrm{p}}$ is the plasma volume, and $H$ is the percent hematocrit. The factor 0.92 accounts for the difference between the central and peripheral hematocrit (32). The interstitial volume was calculated as the difference between the extracellular and the plasma water volume. The intracellular fluid volume was calculated as 
the difference between the total body water volume and the extracellular fluid volume. The volume occupied by the red blood cells was calculated as the difference between blood and plasma volumes.

Because ferrocyanide is exclusively eliminated by the kidneys without tubular secretion or reabsorption, the indicator clearance equals the glomerular filtration rate $\left(q_{\mathrm{f}}\right)(23)$ and can be calculated using Eq. 8.

$q_{\mathrm{f}}=\frac{m_{\mathrm{i}}}{\frac{\mathrm{A}}{\alpha}+\frac{\mathrm{B}}{\beta}+\frac{\mathrm{C}}{\gamma}}($ liter $/ \mathrm{min})$

where $\mathrm{A}, \alpha, \mathrm{B}, \beta, \mathrm{C}$, and $\gamma$ are the same quantities as in Eq. 5 and $6(23)$.

Plasma protein escape rate from the intravascular compartment $\left(q_{\mathrm{p}}\right)$ was calculated from the slope of the Evans blue concentration versus time curve, using Eq. 9:

$q_{\mathrm{p}}=\alpha \cdot \mathrm{t} \cdot 100(\% / \mathrm{h})$

where $\alpha$ is the same quantity as in Eq. 3, and $t$ is time in minutes

Statistical analysis. Data are expressed as mean \pm SEM. Comparison of differences between the shunt and control lambs was done by using the two-tailed Student's $t$ test for unpaired samples (33). The differences between the hormone concentrations at day 4 and at $2.5 \mathrm{wk}$ in each group were tested nonparametrically with the Mann-Whitney test (33). A $P$ value $<0.05$ was considered significant. Correlation coefficients and regression equations have been calculated and reported according to standard techniques $(33,34)$.

\section{Results}

There was no significant difference in body mass between the two groups of lambs ( $13.5 \pm 1$ vs. $13.2 \pm 1 \mathrm{~kg})$. Although there was no selection for either the shunt or the control group, the shunt lambs were older than the control lambs ( $58 \pm 3$ vs. $43 \pm 3$ d; $P<0.01$ ). The left-to-right shunt led to significant hemodynamic differences between both groups (Table I), which were similar to those previously reported from our laboratory (1315). Pulmonary blood flow in the shunt lambs was substan-

\section{Table I. Hemodynamic Data of Shunt and Control Lambs}

\begin{tabular}{|c|c|c|}
\hline & Control & Shunt \\
\hline \multicolumn{3}{|l|}{ Pressures $(m m H g)$} \\
\hline \multicolumn{3}{|l|}{ Aortic } \\
\hline Peak systolic & $90 \pm 3$ & $81 \pm 2 *$ \\
\hline Diastolic & $64 \pm 3$ & $50 \pm 2 *$ \\
\hline Mean & $73 \pm 3$ & $64 \pm 2 *$ \\
\hline Pulmonary arterial, mean & $14 \pm 1$ & $26 \pm 3^{*}$ \\
\hline Left atrial & $4 \pm 1$ & $16 \pm 2^{*}$ \\
\hline Right atrial & $1 \pm 1$ & $8 \pm 1^{*}$ \\
\hline Heart rate (beats/min) & $131 \pm 10$ & $154 \pm 8$ \\
\hline \multicolumn{3}{|l|}{ Blood flow, $\mathrm{ml} \cdot \mathrm{min}^{-1} \cdot \mathrm{kg}^{-1}$} \\
\hline Systemic & $122 \pm 6$ & $124 \pm 10$ \\
\hline Pulmonary & $122 \pm 6$ & $279 \pm 27^{*}$ \\
\hline \multicolumn{3}{|l|}{ Left-to-right shunt (\% of left } \\
\hline ventricular output) & & $55 \pm 3$ \\
\hline Left ventricular stroke volume $(\mathrm{ml} / \mathrm{kg})$ & $0.98 \pm 0.08$ & $1.78 \pm 0.12^{*}$ \\
\hline \multicolumn{3}{|l|}{ Systemic vascular resistance $(\mathrm{mm} \mathrm{Hg}$. } \\
\hline$k g \cdot \min \cdot$ liter $\left.^{-1}\right)$ & $592 \pm 32$ & $456 \pm 43^{*}$ \\
\hline
\end{tabular}

Data are mean \pm SEM. Shunt $n=9$, control $n=11 .{ }^{*}$ Significant difference between shunt and control lambs.
Table II. Body Fluid Compartment Volumes, and Hematologic Data

\begin{tabular}{lcc}
\hline & Control & Shunt \\
\hline Total body water $(\mathrm{ml} / \mathrm{kg})$ & $780 \pm 10$ & $809 \pm 17$ \\
Intracellular fluid volume $(\mathrm{ml} / \mathrm{kg})$ & $499 \pm 10$ & $497 \pm 17$ \\
Extracellular fluid volume $(\mathrm{ml} / \mathrm{kg})$ & $281 \pm 8$ & $312 \pm 4^{*}$ \\
Interstitial fluid volume $(\mathrm{ml} / \mathrm{kg})$ & $221 \pm 9$ & $229 \pm 8$ \\
Plasma volume $(\mathrm{ml} / \mathrm{kg})$ & $61 \pm 5$ & $83 \pm 5^{*}$ \\
Red cell volume $(\mathrm{ml} / \mathrm{kg})$ & $25 \pm 2$ & $29 \pm 2$ \\
Blood volume $(\mathrm{ml} / \mathrm{kg})$ & $84 \pm 7$ & $110 \pm 6^{*}$ \\
Hemoglobin $(\mathrm{g} / \mathrm{dl})$ & $10.3 \pm 0.3$ & $8.8 \pm 0.3^{*}$ \\
Hematocrit $(\%)$ & $30 \pm 1$ & $26 \pm 1^{*}$ \\
\end{tabular}

Data are mean \pm SEM. Shunt $n=9$, control $n=11 .{ }^{*}$ Significant difference between shunt and control lambs.

tially larger than in the control lambs. Despite the runoff of $55 \%$ of left ventricular output to the pulmonary circulation, the shunt lambs were able to maintain their systemic blood flow at the same level as the control lambs. This was predominantly accomplished through a considerably increased left ventricular stroke volume. The left-to-right shunt led to a substantial increase in pulmonary arterial and left atrial pressures. Right atrial pressure in the shunt lambs was also considerably higher than in the control lambs. Aortic pressures in the shunt lambs were significantly lower than in the control lambs. Systemic vascular resistance was also lower in the shunt than in the control lambs.

Plasma volume was $36 \%$ larger in shunt than in control lambs (Table II). There was a significant correlation between the left-to-right shunt and the plasma volume (Fig. 2). Furthermore, there proved to be a significant relationship between plasma volume and left ventricular stroke volume (Fig. 3). Because of the larger plasma volume and the equal red blood cell volume in shunt and control lambs, the blood volume of the shunt lambs was also significantly larger than in control lambs; the hematocrit and hemoglobin concentration of the shunt lambs were lower than in the control lambs (Table II).

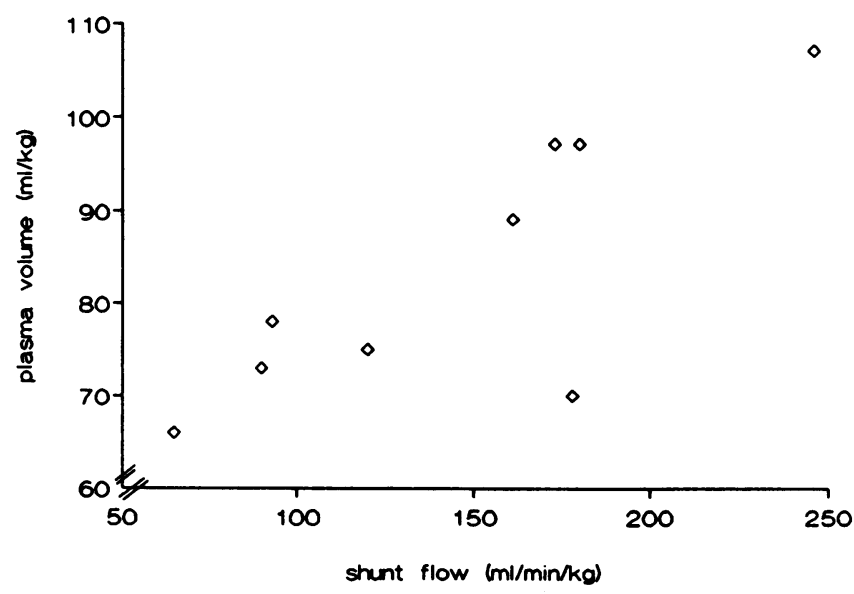

Figure 2. Plasma volume versus left-to-right shunt flow. Correlation coefficient $r=0.81, P<0.01$. Regression equation $y=0.199$ $( \pm 0.05) \cdot x+54.3( \pm 8.3) \mathrm{ml} / \mathrm{kg}$; residual variance: 76.1 . 


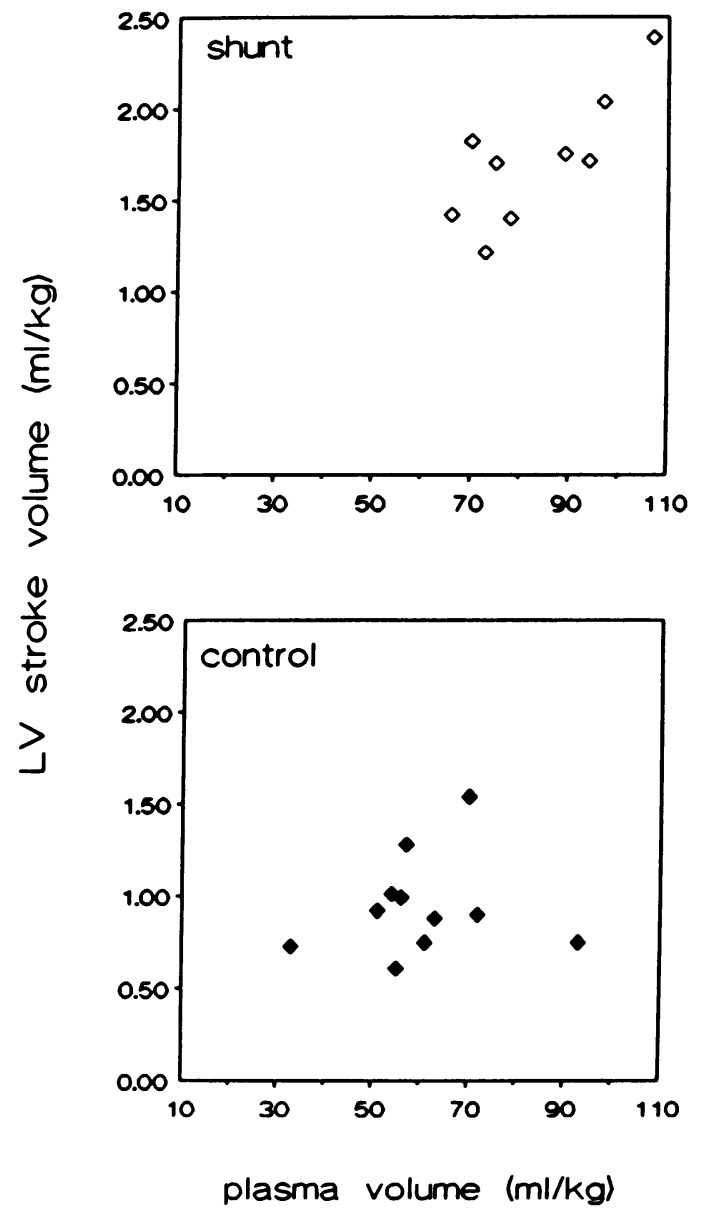

Figure 3. Left ventricular stroke volume of shunt (upper) and control (lower) lambs versus plasma volume. There was a significant correlation in the shunt lambs $(r=0.78, P<0.02)$ but not in the control lambs $(r=0.12)$. Regression equation shunt lambs: $y=0.020$ $( \pm 0.006) \cdot x+0.062( \pm 0.50) \mathrm{ml} / \mathrm{kg}$; residual variance: 0.056 .

Because of the increased plasma volume, the extracellular fluid volume of the shunt lambs was also higher, whereas interstitial volume was not significantly different from that of control lambs. Although the intracellular fluid volume was not significantly different in both groups, total body water volume tended to be higher in shunt than in control lambs, because of the increased extracellular fluid volume, but this did not reach statistical significance.

There was no significant difference in plasma protein concentration between the two groups. Total intravascular protein mass of the shunt lambs, however, was substantially higher than that of control lambs (Table III). Plasma protein escape rate was similar in the two groups ( Table III). Plasma osmolality, plasma sodium, potassium, chloride, urea, creatinin concentrations, and blood gas values were not different between the two groups and there was no significant difference in glomerular filtration rate between shunt and control lambs (Table III). The higher protein mass was not accompanied by a substantial change in plasma protein subdivision, except for a small but significant increase in $\alpha 2$ globulin fraction in shunt lambs as was determined in eight shunt and seven control lambs from our laboratory (Table IV). Plasma albumin/glo-
Table III. Biochemical Data, Protein Escape Rate, and Glomerular Filtration Rate

\begin{tabular}{|c|c|c|}
\hline & Control & Shunt \\
\hline Plasma protein $(\mathrm{g} /$ liter $)$ & $58 \pm 1$ & $60 \pm 2$ \\
\hline \multicolumn{3}{|l|}{ Intravascular protein mass } \\
\hline ( $g / k g$ body mass) & $3.5 \pm 0.2$ & $5.0 \pm 0.3^{*}$ \\
\hline \multicolumn{3}{|l|}{ Plasma protein escape rate } \\
\hline$\left(\% \cdot h^{-1} \cdot k g^{-1}\right)$ & $2.0 \pm 0.3$ & $1.9 \pm 0.3$ \\
\hline Plasma osmolality ( $\mathrm{mmol} /$ liter) & $286 \pm 2$ & $286 \pm 3$ \\
\hline $\mathrm{Na}^{+}($mmol/liter $)$ & $144 \pm 1$ & $145 \pm 1$ \\
\hline $\mathrm{K}^{+}(\mathrm{mmol} /$ liter $)$ & $4.6 \pm 0.1$ & $4.6 \pm 0.2$ \\
\hline $\mathrm{Cl}^{-}($mmol/liter $)$ & $106 \pm 1$ & $106 \pm 2$ \\
\hline Urea (mmol/liter) & $4.3 \pm 0.5$ & $5.1 \pm 0.7$ \\
\hline Creatinin ( $\mathrm{mmol} /$ liter) & $61 \pm 7$ & $66 \pm 7$ \\
\hline \multicolumn{3}{|l|}{ Glomerular filtration rate } \\
\hline$\left(m l \cdot \min ^{-1} \cdot k g^{-1}\right)$ & $2.7 \pm 0.1$ & $2.6 \pm 0.3$ \\
\hline \multicolumn{3}{|l|}{ Arterial } \\
\hline $\mathrm{pH}$ & $7.43 \pm 0.01$ & $7.42 \pm 0.02$ \\
\hline $\mathrm{PCO}_{2}(\mathrm{~mm} \mathrm{Hg})$ & $39 \pm 1$ & $41 \pm 1$ \\
\hline $\mathrm{PO}_{2}(m m \mathrm{Hg})$ & $107 \pm 2$ & $102 \pm 3$ \\
\hline $\mathrm{HCO}_{3}^{-}$(mmol/liter) & $24.6 \pm 0.7$ & $25.3 \pm 1.2$ \\
\hline
\end{tabular}

Data are mean \pm SEM. Shunt $n=9$, control $n=11 .{ }^{*}$ Significant difference between shunt and control lambs.

bulin ratio was not significantly different either between shunt and control lambs: $1.13 \pm 0.07$ vs. $1.37 \pm 0.14$, respectively.

Plasma renin activity of the shunt lambs measured at 2.5 wk after surgery was significantly higher than in control lambs: $8.0 \pm 2.2 \mathrm{vs.} 1.6 \pm 0.2 \mathrm{nmol} \cdot 1^{-1} \cdot \mathrm{h}^{-1}$. The higher plasma aldosterone concentration did not reach statistical significance: $0.51 \pm 0.14$ vs. $0.24 \pm 0.09 \mathrm{nmol} /$ liter, $P=0.11$. Because it has recently been demonstrated that the changes in renin and aldosterone are transient and may take place within the first week after creation of the shunt (6), we measured the activity of these hormones and of arginine-vasopressin at day 4 as well as at $2.5 \mathrm{wk}$ after surgery in some lambs. Early ( $4 \mathrm{~d})$ after creation of the shunt, plasma renin activities and plasma aldosterone concentrations of the shunt lambs were $\sim 10$-fold higher than in than in control lambs (Fig. 4). This difference did not reach statistical significance, probably because of the small numbers

Table IV. Plasma Protein Subdivision

\begin{tabular}{lcc}
\hline & Control & Shunt \\
\hline Total protein (g/liter) & $61 \pm 2$ & $61 \pm 1$ \\
Albumin (\% of total protein) & $57 \pm 3$ & $52 \pm 2$ \\
Globulins (\% of total protein) & & \\
$\alpha 1$ & $2 \pm 0$ & $3 \pm 1$ \\
$\alpha 2$ & $18 \pm 1$ & $21 \pm 1^{*}$ \\
$\beta$ & $10 \pm 1$ & $12 \pm 1$ \\
$\gamma$ & $13 \pm 2$ & $11 \pm 1$ \\
\hline
\end{tabular}

Data are mean \pm SEM. Data are from similarly instrumented lambs (shunt $n=8$, control $n=7$ ) from our laboratory at 2 wk after surgery (30). * Significant difference between shunt and control lambs. 

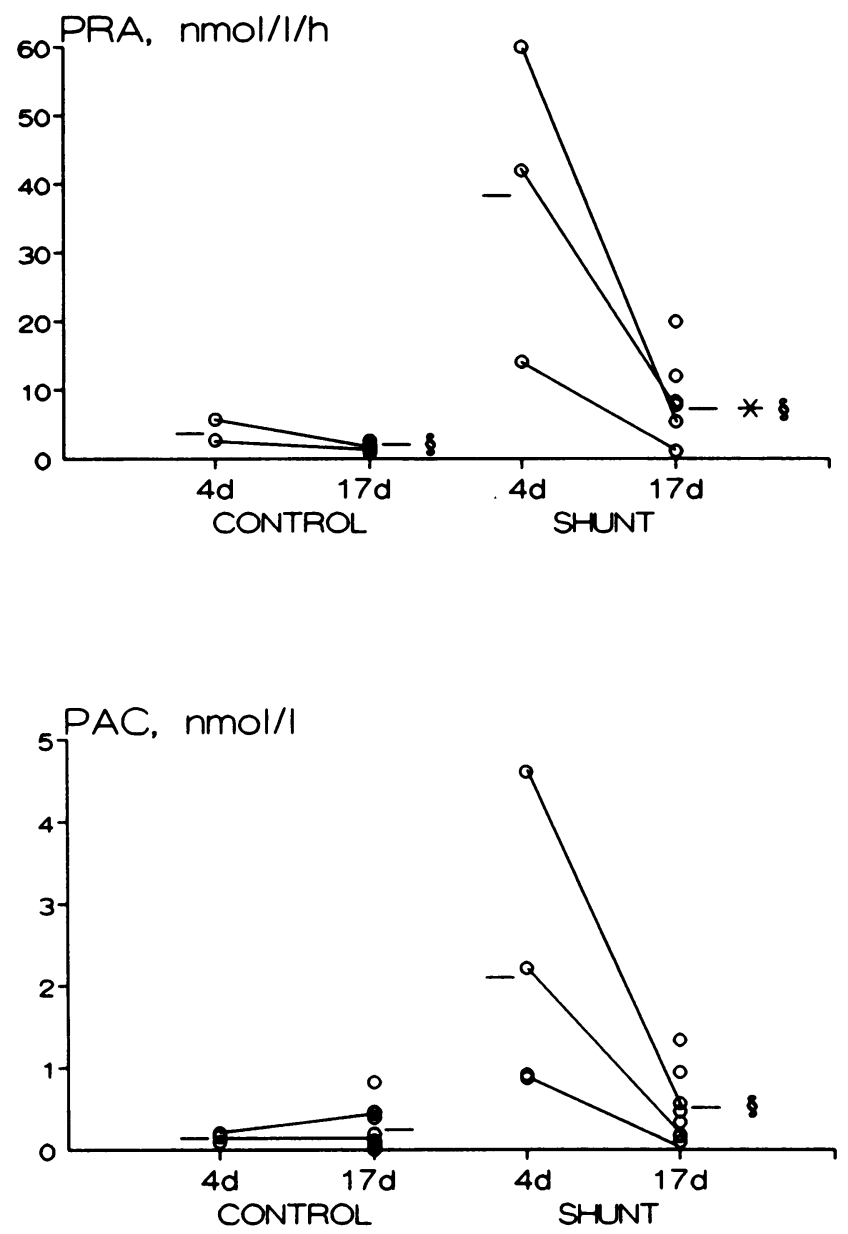

Figure 4. Plasma renin activity $(P R A)$ and plasma aldosterone concentration $(P A C)$, in control and shunt lambs at days 4 and 17 after surgery. Mean values are indicated by a dash immediately next to the circles representing the individual values. Paired measurements in one lamb are connected by a line. SSignificant difference between days 4 and 17 after surgery in one group, *Significant difference between shunt and control lambs at corresponding times. Renin conversion factor $\mathrm{nmol} \cdot \mathrm{l}^{-1} \cdot \mathrm{h}^{-1}$ to $\mathrm{ng} \cdot \mathrm{ml}^{-1} \cdot \mathrm{h}^{-1}: \times 0.46$; aldosterone conversion factor $\mathrm{nmol} /$ liter to $\mathrm{pg} / \mathrm{ml}: \times 360$.

in these subgroups. In the shunt lambs, both plasma renin activities and plasma aldosterone concentrations decreased signifcantly with time (Fig. 4). In control lambs only a small decrease in plasma renin activity occurred, whereas plasma aldosterone concentration did not change significantly between day 4 and $2.5 \mathrm{wk}$. When all plasma renin activities and aldosterone concentrations of the shunt lambs are plotted against the number of days after surgery, including the early determinations, a significant negative correlation is observed for plasma renin activity $(r=-0.78, P<0.01, y=47( \pm 10)-2.2( \pm 0.6) \cdot x$ $\mathrm{nmol} \cdot 1^{-1} \cdot \mathrm{h}^{-1}$, residual variance: 171$)$ as well as for plasma aldosterone concentration $(r=-0.71, P<0.02, y=3.0( \pm 0.7)$ $-0.14( \pm 0.05) \cdot x \mathrm{nmol} /$ liter, residual variance 1.0$)$.

Arginine-vasopressin concentrations were not significantly different between the two groups at 2.5 wk after surgery: $8.0 \pm 1.3$ vs. $7.4 \pm 1.3 \mathrm{ng} / \mathrm{liter}$, nor did significant differences exist between early and late after surgery or a correlation with the number of days after surgery.

\section{Discussion}

Our data show that blood volume is increased in lambs with an aortopulmonary shunt. This is realized by an increase in plasma volume, whereas the red blood cell volume is unchanged. As a consequence, the hemoglobin is diluted. The adaptation to the left-to-right shunt, an increase in blood volume, thus is similar to that observed in mature dogs with aortocaval left-to-right shunts and humans with arteriovenous fistulas $(2,3)$ and may serve to compensate for the effects of a too low circulating blood volume on cardiac performance. In dogs with acute left-to-right shunts cardiac performance was shown to be limited by blood volume, although no blood was lost (35). Opening of a large aortocaval fistula led to an increase in left ventricular output, but effective systemic blood flow fell below control values because the increase in left ventricular output was not large enough to compensate for the shunt flow. Subsequent infusion of saline solution led to a further increase in left ventricular output so that the shunt flow could be compensated for and systemic blood flow returned to control values, whereas the left-to-right shunt flow did not change. These experiments in dogs suggest that retention of fluid to increase plasma and blood volume is useful for enhancing left ventricular performance in subjects with large left-to-right shunts. In fact, this did occur in the shunt lambs of the present study: there even was a clear relationship between the magnitude of the stimulus (magnitude of the left-to-right shunt) and the response (plasma volume increase) (Fig. 2). Moreover, there proved to be a significant relationship between plasma volume and left ventricular stroke volume (Fig. 3), demonstrating the relevance of the adaptation for cardiac function in the shunt lambs.

As expected from studies in mature individuals with left-toright shunts, the mediator of the increase in plasma volume in the shunt lambs is a transient increase in renin activity and aldosterone concentration that is accompanied by a transient retention of sodium and water $(6,36)$. That the higher aldosterone concentration in the shunt compared to the control lambs did not reach statistical significance was probably due to the original design of our study, which included measurement of the hormone concentrations at $17 \pm 1 \mathrm{~d}$ after creation of the left-to-right shunt, simultaneously with the measurement of the body fluid compartments. However, regression analysis, including early measurements at day 4 , revealed a significant negative correlation between plasma renin activity as well as aldosterone concentration with time after opening of the leftto-right shunt, which demonstrates that the renin and aldosterone response of the lambs to the opening of an aortopulmonary left-to-right shunt follows the same pattern as found in adult dogs with aortocaval shunts (6). Although a low blood volume and a decrease in aortic blood pressure are strong stimuli for arginine-vasopressin release (37), no difference in plasma arginine-vasopressin concentration or its relation with time after creation of the shunt was found between shunt and control lambs. It may be that the arginine-vasopressin release is inhibited by the increased left atrial pressure (37) or only plays a part immediately after opening of a left-to-right shunt.

One would expect that an isosmotic water retention that results from an increase in aldosterone concentration, for which the equal osmolalities in the two groups give evidence, leads to an increase in both subcompartments of the extracellular fluid volume. In the shunt lambs, however, only the plasma 
volume is increased whereas the interstitial volume is not significantly different from that in the control lambs. This specific increase in plasma volume in the shunt lambs is realized by an increased plasma protein mass, which keeps the retained water within the vascular compartment. Since $1 \mathrm{~g}$ of protein binds $\sim 15 \mathrm{ml}$ of water (38), the $1.5 \mathrm{~g} / \mathrm{kg}$ increase in intravascular protein mass matches the $22 \mathrm{ml} / \mathrm{kg}$ increase in plasma volume.

The mechanism for the increase in intravascular protein mass could be an increased protein production by the liver or a shift of protein from the extravascular to the intravascular compartment. The latter occurs in pregnancy, which is also a state of decreased peripheral vascular resistance, activated renin-aldosterone system, and increased plasma volume (5). During pregnancy protein production is suppressed by the increased estrogen and progesterone concentrations (39). A shift of protein from the extravascular to the intravascular compartment allows for an increase in transcapillary colloid osmotic pressure difference and thus for an increase in plasma volume. Although this mechanism is possible during the early time after opening of the left-to-right shunt, it is not likely the cause of the increased intravascular protein mass at $2.5 \mathrm{wk}$ after surgery because the new equilibrium over the microvascular wall would have been reached at a plasma protein concentration lower than that prevailing before the volume expansion set in. In addition, an extra- to intravascular protein shift would have been accompanied by an increased transcapillary colloid osmotic pressure difference, leading to a larger increase in plasma volume than that caused by an isolated $1.5 \mathrm{~g} / \mathrm{kg}$ intravascular protein increase. Moreover, an increased intra- to extravascular protein difference would require increased lymph flow to maintain this increased protein gradient $(40,41)$ and we have no evidence for that because protein escape rate is not different between shunt and control lambs.

More likely, the increased intravascular protein mass results from increased albumin and globulin production in the liver as a result of the decrease in colloid osmotic pressure accompanying the initial aldosterone-induced $\mathrm{H}_{2} \mathrm{O}$ retention (42). A similar course of events has been reported for humans during $8 \mathrm{~d}$ of heavy exercise training (16). In this study a ninefold increase in plasma renin activity and arginine-vasopressin concentration induced $\mathrm{Na}^{+}$and $\mathrm{H}_{2} \mathrm{O}$ retention, which was retained intravascularly by a progressive increase in plasma albumin content. In persons subjected to longer periods of training, albumin as well as liver-produced globulins $(\alpha, \beta)$ are increased $(38,43)$. Similar to in our lambs, this is not accompanied by a substantial change in plasma protein profile, as deduced from albumin/globulin ratio ( 1.8 vs. 2.0 , athletes vs. sedentary subjects ), although $\alpha 2$ globulin fraction is higher than in sedentary subjects (38).

Cardiac disease with decreased myocardial performance, in absence of a left-to-right shunt, may also lead to fluid retention, increased extracellular fluid volume, and increased cardiac filling pressures $(5,17-20)$. In our shunt lambs classical symptoms and signs of congestive heart failure were present: tachycardia, increased atrial filling pressures, hepatomegaly (37\% increase in liver weight compared with controls) (30), respiratory distress (as deduced from the $71 \%$ increase in diaphragmatic blood flow) (30), and increased atrial natriuretic factor ( $422 \pm 77$ vs. $85 \pm 14 \mathrm{ng} /$ liter) (30). However, we do not think that they are signs of an impairment of myocardial performance. This is concluded not only from the fact that systemic blood flow could be maintained at the same level as in control lambs without reduction in renal blood flow (30) or disturbances in blood gas values or renal function, but also from data of exercise studies in similar shunt lambs. During maximum exercise, left ventricular output was increased to a significantly higher level than in control lambs $(448 \pm 27$ vs. $359 \pm 23$ $\left.\mathrm{ml} \cdot \min ^{-1} \cdot \mathrm{kg}^{-1}\right)(15)$.

With regard to the clinical setting, our study demonstrates that, in the first weeks of a manifest aortopulmonary left-toright shunt, fluid retention leading to increased blood volume seems to be a good adaptation because it increases stroke volume and thus contributes to maintaining an adequate systemic blood flow. The increased blood volume, however, will result in higher filling pressures and therefore in signs of venous congestion, such as respiratory distress and hepatomegaly. Later on, interstitial fluid may increase, which may show as edema. Usually the signs of venous congestion are suppressed by giving diuretics to decrease the (suspected) excess interstitial fluid. Other studies have demonstrated that administration of diuretics does not decrease plasma volume $(44,45)$. If this also applies to individuals with left-to-right shunts, it would imply that the increase in blood volume is not disturbed by diuretic treatment. Beside diuretics, digoxin is quite often used in children with signs of circulatory congestion resulting from large left-to-right shunts in order to increase left ventricular output and thus systemic blood flow (46). However, only a small percentage of these children show a positive inotropic response (46), which may be due to the fact that contractility is usually high in newborns (47). The results of our study suggest that the administration of concentrated albumin solution could be beneficial because it supports the physiological adaptation. However, it would probably also increase cardiac filling pressures and consequently atrial natriuretic factor concentration. Recent studies have shown that increased concentrations of atrial natriuretic factor shift proteins from the intravascular to the interstitial compartment (48). This counteracts the initial adaptation and could be a factor in the initiation of edema formation. In addition, increased filling pressures increase wall stress and hence could increase myocardial $\mathrm{O}_{2}$ demand. Thus further studies examining the administration of concentrated albumin solution in combination with diuretics are needed to assess the hypothesized beneficial effects on systemic blood flow and possible unwanted side effects to determine optimal supportive therapy in case of a substantial left-to-right shunt.

In conclusion, blood volume in lambs with an aortopulmonary shunt is increased through an expansion of plasma volume at $2.5 \mathrm{wk}$ after creation of the left-to-right shunt. The plasma volume increase is closely related to the magnitude of the left-to-right shunt flow and probably forms a compensation for the shunt-induced decrease in effective circulating blood volume. There were no signs of impairment of cardiac function. Furthermore, our data demonstrate that the plasma volume increase is realized by an early, transient increase in renin and aldosterone concentrąions. Through an increase in the total amount of plasma protein the retained fluid is kept in the intravascular compartment so that interstitial volume does not increase.

\section{Acknowledgments}

The authors express their gratitude to Mrs. A. K. van Zanten and her coworkers for the plasma renin activities and arginine-vasopressin determinations and to Dr. J. J. Pratt and coworkers for aldosterone deter- 
minations (Gamma and Beta Isotope Laboratory, respectively, Department of Nuclear Medicine, University Hospital, Groningen); to E. E. Ligeon and coworkers (Central Clinical Chemical Laboratory, University Hospital, Groningen ) for electrolyte, urea, and creatinin determinations; to Janny Takens (Department of Pediatric Cardiology, University Hospital, Groningen) for protein electrophoresis; and to Ineke Wessels for editorial assistance during the preparation of this manuscript.

This study was partially supported by a grant from the Jan Kornelis De Cock Foundation and the Netherlands Heart Foundation (85.089).

\section{References}

1. Rudolph, A. M., E. M. Scarpelli, R. J. Golinko, and N. L. Gootman. 1964. Hemodynamic basis for clinical manifestations of patent ductus arteriosus. Am. Heart J. 68:447-458.

2. Warren, J. V., D. C. Elkin, and J. L. Nickerson. 1951. The blood volume in patients with arteriovenous fistulas. J. Clin. Invest. 30:220-226.

3. Epstein, F. H., and T. B. Ferguson. 1955. The effect of the formation of an arteriovenous fistula upon blood volume. J. Clin. Invest. 34:434-438.

4. Gazzaniga, A. B., R. L. Replogle, R. E. Gross. 1966. Blood volume changes following closure of intracardiac left-to-right shunts. JAMA (J. Am. Med. Assoc.). 198:989-992.

5. Schrier, R. W. 1988. Pathogenesis of sodium and water retention in highand low-output cardiac failure, nephrotic syndrome, cirrhosis and pregnancy; part I. N. Engl. J. Med. 319:1065-1072.

6. Villarreal, D., R. H. Freeman, J. O. Davis, K. M. Verburg, R. C. Vari. 1987. Atrial natriuretic factor secretion in dogs with experimental high-output heart failure. Am. J. Physiol. 252:H692-H696.

7. Rudolph, A. M., J. Itskovitz, H. S. Iwamoto, M. L. Reuss, M. A. Heymann. 1981. Fetal cardiovascular response to stress. Semin. Perinatology. 5:109-121.

8. Heymann, M. A., H. S. Iwamoto, A. M. Rudolph. 1981. Factors affecting changes in the neonatal systemic circulation. Annu. Rev. Physiol. 43:371-483.

9. Scammell, A. M., M. J. Driver. 1988. Plasma aldosterone and renin activity. Arch. Dis. Child. 63:139-141.

10. Boucek, M. M., R. Chang, D. P. Synhorst. 1989. Renin-angiotensin II response to the hemodynamic pathology of ovines with ventricular septal defect. Circ. Res. 64:524-531.

11. Badke, F. R., F. C. White, M. L. Winter, J. Covell, J. Andres, C. Bloor. 1981. Effects of experimental volume-overload hypertrophy on myocardial blood flow and cardiac function. Am. J. Physiol. 241:H564-H570.

12. Legault, F., J. L. Rouleau, C. Jumeau, C. Rose, K. Rakusan. 1990. Functional and morphological characteristics of compensated and decompensated cardiac hypertrophy in dogs with chronic infrarenal aorto-caval fistulas. Circ. Res. 66:846-859.

13. Toorop, G. P., R. Hardjowijono, M. Dalinghaus, A. M. Gerding, J. H. Koers, W. G. Zijlstra, J. R. G. Kuipers. 1987. Myocardial blood flow and $\mathrm{VO}_{2}$ in conscious lambs with an aortopulmonary shunt. Am. J. Physiol. 252:H681H686.

14. Toorop, G. P., R. Hardjowijono, M. Dalinghaus, J. H. Koers, C. R. H. Wildevuur, W. G. Zijlstra, J. R. G. Kuipers. 1987. Comparative circulatory effects of isoproterenol, dopamine, and dobutamine in conscious lambs with and without aortopulmonary left-to-right shunts. Circulation. 75:1222-1228.

15. Gratama, J. W. C., J. J. Meuzelaar, M. Dalinghaus, J. H. Koers, A. J. Werre, W. G. Zijlstra, J. R. G. Kuipers. 1990. Maximal exercise capacity and oxygen consumption of lambs with an aortopulmonary left-to-right shunt. $J$. Appl. Physiol. 69:1479-1485.

16. Convertino, V. A., P. J. Brock, L. C. Keil, E. M. Bernauer, J. E. Greenleaf. 1980. Exercise training-induced hypervolemia: role of plasma albumin, renin, and vasopressin. J. Appl. Physiol. 48:665-669.

17. Watkins, L., Jr., J. A. Burton, J. R. C. E. Haber, F. W. Smith, A. C. Barger. 1976. The renin angiotensin system in congestive heart failure in conscious dogs. J. Clin. Invest. 57:1606-1617.

18. Fauchald, P. 1985. Colloid osmotic pressures, plasma volume, and interstitial volume in patients with heart failure. Scand. J. Clin. Lab. Invest. 45:701706.

19. Dyckner, T., P.-O. Wester. 1986. Salt and water balance in congestive heart failure. Acta Med. Scand. Suppl. 707:27-31.

20. Anand, I. S., R. Ferrari, G. S. Kalra, P. L. Wahi, P. A. Poole-Wilson, P. C. Harris. 1989. Edema of cardiac origin. Studies of body water and sodium, renal function, hemodynamic indexes, and plasma hormones in untreated congestive heart failure. Circulation. 80:299-305.

21. Artman, M., M. D. T. P. G. Parrish, Jr. 1983. Congestive heart failure in childhood and adolescence: recognition and management. Am. Heart J. 105:471-480.

22. Badr, K. F., I. Ichikawa. 1988. Prerenal failure: a deleterious shift from renal compensation to decompensation. N. Engl. J. Med. 319:623-629.

23. De Graaf, S. S. N. 1986. The assessment of body fluid volumes by indicator dilution: general methodology. In Cancer Chemotherapy and Body Fluid Volumes. Thesis. University Press, Groningen, The Netherlands. 5-21.

24. Zweens, J., H. Frankena. 1981. An improved method for the determination of the plasma volume with Evans blue. J. Clin. Chem. Clin. Biochem. 19:919-924.

25. Zweens, J., H. Frankena, W. G. Zijlstra. 1978. The effect of pentobarbital anaesthesia upon the extracellular fluid volume in the dog, studied by continuous infusion and single injection. Pfluegers Arch. Eur. J. Physiol. 376:131-138.

26. Zweens, J., H. Frankena, W. G. Zijlstra. 1980. Infrared-spectrometric determination of $\mathrm{D}_{2} \mathrm{O}$ in biological fluids. Reappraisal of the method and application to the measurement of total body water and daily water turnover in the dog. Pfluegers Arch. Eur. J. Physiol. 385:71-77.

27. Kuipers, J. R. G., D. Sidi, M. A. Heymann, A. M. Rudolph. 1982. Comparison of methods of measuring cardiac output in newborn lambs. Pediatr. Res. 16:594-598.

28. Doumas, B. T. 1975. Standards for total serum protein assays-a collaborative study. Clin. Chem. 21:1159-1166.

29. Pratt, J. J., R. Booman, M. G. Woldring, A. J. M. Donker. 1978. Special problems in the radio-immunoassay of plasma aldosterone without prior extraction and purification. Clin. Chim. Acta. 84:329-337.

30. Gratama, J. W. C., J. J. Meuzelaar, M. Dalinghaus, J. H. Koers, S. Gratama, W. G. Zijlstra, and J. R. G. Kuipers. 1992. Distribution of systemic blood flow in lambs with an aortopulmonary shunt during strenuous exercise. J. Appl. Physiol. In press.

31. Zweens, J., H. Frankena, P. Rispens, W. G. Zijlstra. 1975. Determination of extracellular fluid volume in the dog with ferrocyanide. Pfluegers Arch. Eur. J. Physiol. 357:275-290.

32. Gregersen, M. I., R. A. Rawson. 1959. Blood volume. Physiol. Rev. 39:307-341.

33. Zar, J. H. 1984. Biostatistical Analysis. Prentice Hall Inc. Englewood Cliffs, NJ 126-131, 138-145, 261-272, 306-309.

34. Godfrey, K. 1986. Simple linear regression in medical research. In Medical Uses of Statistics. J. C. Bailar III, and F. Mosteller, editors. New England Journal of Medicine Books, Waltham, MA. 170-204.

35. Frank, C. W., H.-H. Wang, J. Lammerant, R. Miller, R. Wégria. 1955. An experimental study of the immediate hemodynamic adjustments to acute arteriovenous fistulae of various sizes. J. Clin. Invest. 34:722-731.

36. Guyton, A. C., C. E. Jones, and T. G. Coleman. 1973. Effect of A-V fistulas and cardiac shunts on cardiac output. In Circulatory Physiology: Cardiac Output and its Regulation. A. C. Guyton, C. E. Jones, and T. G. Coleman, editors. W. B. Saunders Company, Philadelphia, PA. 412-426.

37. Share, L. 1988. Role of vasopressin in cardiovascular regulation. Physiol. Rev. 68:1248-1284.

38. Röcker, L., K. A. Kirsch, H. Stoboy. 1976. Plasma volume, albumin and globulin concentrations, and their intravascular masses. A comparative study in endurance athletes and sedentary subjects. Eur. J. Appl. Physiol. Occup. Physiol. 36:57-64.

39. Joseph, J. C., C. Baker, M. L. Sprang, E. W. Bermes. 1978. Changes in plasma proteins during pregnancy. Ann. Clin. Lab. Sci. 8:130-141.

40. Fadnes, H. O., P. Øian. 1989. Transcapllary fluid balance and plasma volume regulation: a review. Obstet. Gynecol. Surv. 44:769-773.

41. Aukland, K., G. Nicolaysen. 1981. Interstitial fluid volume: local regulatory mechanisms. Physiol. Rev. 61:556-643.

42. Rothschild, M. A., M. Oratz, S. S. Schreiber. 1972. Albumine synthesis. Part 1. N. Engl. J. Med. 286:748-757.

43. Koch, G., L. Röcker. 1977. Plasma volume and intravascular protein masses in trained boys and fit young men. J. Appl. Physiol. 43:1085-1088.

44. O'Donovan, B. H., E. F. Bell. 1989. Effects of furosemide on body water compartments in infants with bronchopulmonary dysplasia. Pediatr. Res. 26:121-124.

45. Schuster, C.-J., M. H. Weil, J. Besso, M. Carpio, R. J. Henning. 1984. Blood volume during diuresis induced by furosemide. Am. J. Med. 76:585-592. 46. Berman, W., Jr., S. M. Yabek, T. Dillon, C. Niland, S. Corlew, D. Christensen. 1983. Effect of digoxin in infants with a congested circulatory state due to a ventricular septal defect. $N$. Engl. J. Med. 308:363-366.

47. Teitel, D. F., D. Sidi, T. Chin, C. Brett, M. A. Heymann, A. M. Rudolph. 1985. Developmental changes in myocardial contractile reserve in the lamb. $P e$ diatr. Res. 19:948-955.

48. Zimmerman, R. S., N. C. Trippodo, A. A. MacPhee, A. J. Martinez, R. W. Brabee. 1990. High-dose atrial natriuretic factor enhances albumin escape from the systemic but not from the pulmonary circulation. Circ. Res. 67:461-468. 